\title{
ATIVIDADE DA RUBISCO E DAS ENZIMAS DE SÍNTESE E HIDRÓLISE DE SACAROSE, ASSOCIADA À PRODUTIVIDADE DE LÁTEX, EM CLONES DE SERINGUEIRA [Hevea brasiliensis (Willd ex. Adr. de Juss.) Muell.-Arg] CULTIVADOS EM LAVRAS, MG
}

\author{
Activity of rubisco and enzymes of sucrose synthesis and hydrolysis associated to latex \\ productivity, in rubber tree clones [Hevea brasiliensis (Willd ex. Adr. de Juss.) \\ Muell.-Arg] cultivated in Lavras, MG
}

\author{
Paulo Araquém Ramos Cairo ${ }^{1}$, Luiz Edson Mota de Oliveira ${ }^{2}$, Alessandro Carlos Mesquita ${ }^{3}$, Roberto Lisboa Cunha ${ }^{4}$
}

\section{RESUMO}

Estudos já realizados sobre clones de seringueira cultivados no estado de Minas Gerais têm fornecido indícios que permitem supor a existência de uma possível associação entre a variabilidade fotossintética e a produção de látex. Contudo, ainda é escasso o conhecimento acerca da assimilação de $\mathrm{CO}_{2}$ e o transporte de carbono das folhas até a casca, onde a biossíntese de látex ocorre de forma mais intensa. Em todas as etapas desses metabolismos, as reações são reguladas por algumas enzimas-chave. Este trabalho propôsse a avaliar a atividade da Rubisco e das principais enzimas de síntese e hidrólise de sacarose, em plantas de um jardim clonal de seringueira pertencentes aos clones RRIM 600, GT 1 e FX 2261, e sua relação com o desempenho produtivo de plantas adultas e em franca produção. Os resultados sugeriram uma provável associação entre a atividade da Rubisco e das invertases (ácida e neutra) e o desempenho produtivo dos clones. Não houve evidências de tal associação, em relação à sacarose-fosfato sintase (SPS) e à sacarose sintase (SuSy), cujas atividades não diferiram entre os clones avaliados. A hidrólise de sacarose na casca foi exercida predominantemente pela ação da invertase ácida. Em proporções menores e equivalentes, essa atividade foi complementada pela SuSy e pela invertase neutra.

Termos para indexação: Seringueira, enzimas, látex.

\section{ABSTRACT}

Previous researches on rubber tree clone cultivation in Minas Gerais state have provided evidences for a possible association between photosynthetic variability and latex production. Nevertheless, knowledge about the $\mathrm{CO}_{2}$ assimilation and carbon transport from leaves to bark, where the latex biosynthesis is higher, is still scarce. In all steps of these metabolisms, the reactions are regulated by some key enzymes. The aim of this work was to evaluate the Rubisco and the main enzymes of sucrose synthesis and hydrolysis activities in rubber tree plants from a clonal garden, identified as RRIM 600, GT 1, and FX 2261 clones, and their relationship to rubber productivity in the adult plants. The results suggested that the activities of Rubisco and invertases (acidic and neutral) are probably associated to the rubber productivity. This association was no clear in relation to sucrose-phosphate synthase (SPS) and sucrose synthase (SuSy), whose activity showed no difference among the clones. The sucrose hydrolysis in the bark was predominantly catalyzed by the acidic invertase. In smaller and equivalent proportions, sucrose hydrolysis was complemented by the SuSy and neutral invertase activity.

Index terms: Rubber tree, enzymes, latex.

(Recebido em 2 de maio de 2007 e aprovado em 2 de junho de 2008)

\section{INTRODUÇÃO}

Nos últimos anos, a produção mundial de borracha natural de seringueira [Hevea brasiliensis (Willd ex. Adr. de Juss.) Muell.-Arg.] tem sofrido flutuações, a despeito do crescimento linear do seu consumo. Em 2005, a produção mundial, em toneladas, foi de 8.682 mil, para um consumo de
8.742 mil (IRSG, 2006). Cerca de $90 \%$ dessa produção tem origem em países asiáticos. No Brasil, a produção anual, em toneladas, de pouco mais de 100 mil, é insuficiente para atender ao consumo interno de 260 mil (GAMEIRO, 2004). A solução para minimizar a importação de borracha natural tem sido a expansão da heveicultura, com plantas de alta produtividade e látex de boa qualidade (ALVARENGA et al., 2003).

\footnotetext{
${ }^{1}$ Engenheiro Agronômico, Doutor em Fisiologia Vegetal, Professor Adjunto - Departamento de Fitotecnia e Zootecnia/DFZ - Universidade Estadual do Sudoeste da Bahia/UESB - Estrada do Bem-Querer, Km 4 - Cx. P. 95 - 45083-900 - Vitória da Conquista, BA - pcairo@uol.com.br ¿Engenheiro Agronômico, Doutor em Ciências, Professor Titular - Departamento de Biologia/DBI - Setor de Fisiologia Vegetal - Universidade Federal de Lavras/UFLA - Cx. P. 3037 - 37200-000 - Lavras, MG - ledson@ufla.br

${ }^{3}$ Engenheiro Agronômico, Doutor em Fisiologia Vegetal - Rua Vereador Leônidas de Souza Lima, 100 - 37200-000 - Lavras, MG - mesquita@ufla.br ${ }^{4}$ Biólogo, Doutor em Fisiologia Vegetal - Pesquisador EMBRAPA Amazônia Oriental, Agroenergia - Travessa Dr. Enéas Pinheiro, s/n - 66095-100 Belém, PA - ecolisboa@yahoo.com.br
} 
As regiões brasileiras de cultivo tradicional da seringueira são a Amazônia Tropical Úmida, Mato Grosso e Bahia. A expansão da heveicultura privilegiou regiões cujo ambiente é desfavorável ao desenvolvimento do fungo Microcyclus ulei P. Henn V. Arx., causador do "mal sulamericano das folhas" e principal obstáculo ao desenvolvimento da seringueira nas regiões tradicionais de cultivo no Brasil (ROCHA NETO, 1979). No estado de Minas Gerais, que responde por 2,5\% da produção nacional, a heveicultura está se expandindo no Sul de Minas, Triângulo Mineiro, Zona da Mata, Alto do São Francisco e Vale do Rio Doce. Segundo Mesquita (2006a), a produtividade máxima anual dos seringais mineiros é de $1.500 \mathrm{~kg} / \mathrm{ha}$, sendo superior à de tradicionais países produtores, tais como Tailândia $(1.100 \mathrm{~kg} / \mathrm{ha})$, Indonésia (750 kg/ha) e Malásia (1.000 kg/ha).

A biossíntese de látex resulta de uma complexa cadeia de eventos biofísicos, nutricionais e metabólicos, que se relacionam com as condições ambientais, produção e transporte de assimilados, disponibilidade de carboidratos de reserva e demanda por outros drenos. A utilização do látex como principal objeto de exploração econômica da seringueira induz à formação de drenos não convencionais na casca, onde são efetuadas as sangrias. As sangrias freqüentes, que se sucedem à abertura do painel, tendem a estimular o sistema de assimilação de $\mathrm{CO}_{2}$ e transporte de carbono a atender à demanda de carboidratos para a biossíntese renovada de látex na casca.

Estudos realizados por Mesquita (2006b) sugeriram que a produtividade de alguns clones de seringueira pode ter relação com características fisiológicas e bioquímicas do sistema fonte-dreno, as quais podem estar associadas tanto aos processos de assimilação e transporte de carbono, como à utilização de assimilados na biossíntese de borracha natural. Miguel (2005) e Miguel et al. (2007) observaram que em seringais cultivados na cidade de Lavras, MG, os elevados valores de fotossíntese líquida $\left(\mu \mathrm{mol} \mathrm{CO}_{2} \cdot \mathrm{m}^{-2} \cdot \mathrm{s}^{-1}\right)$ do clone RRIM 600 podem estar associados às altas produções de borracha natural desse clone, conforme atestam os trabalhos sobre desempenho produtivo realizados por Lima et al. (2002), Mesquita (2006a) e Oliveira (1999). Contudo, as avaliações de Miguel (2005) basearam-se apenas em informações sobre trocas gasosas e eficiência fotoquímica dos fotossistemas. Novos estudos sobre a atividade de algumas das principais enzimas que atuam nesses processos poderiam elucidar melhor a relação entre a assimilação de $\mathrm{CO}_{2}$, o transporte de carbono a partir dos locais de síntese primária de carboidratos simples e o consumo dos assimilados nos órgãos que os utilizam como precursores da biossíntese de látex.
A ribulose-1,5-bisfosfato carboxilase oxigenase (Rubisco) é uma enzima-chave nas reações de assimilação de $\mathrm{CO}_{2}$, com ação decisiva para a eficiência de carboxilação, com reflexos importantes na atividade fotossintética. Para haver exportação de assimilados a partir dos tecidos-fonte, a conversão prévia de carboidratos primários a sacarose precede o carregamento do floema, cujas reações têm a sacarose-P sintase (SPS) como enzima-chave. Nas células laticíferas do caule, o descarregamento do floema se dá por meio da hidrólise enzimática da sacarose, catalisada por invertase (e suas isoformas) e sacarose sintase (SuSy), produzindo hexoses precursoras da biossíntese do látex.

$\mathrm{Na}$ literatura, não há registro de informações sobre a atividade da Rubisco e da SPS, em seringueira. Existe, portanto, uma ampla demanda de estudos que abordem a atividade dessas enzimas e sua possível associação com o desempenho produtivo dos clones. Mesquita et al. (2006b) buscaram estabelecer correlação entre a atividade da invertase e da SuSy no látex e a produção de alguns clones cultivados em Lavras, MG. Em tecidos da casca, contudo, pouco se conhece sobre uma possível associação entre a atividade das enzimas sacarolíticas e o desempenho produtivo.

Objetivou-se, no presente trabalho, avaliar, em plantas de seringueira oriundas de um jardim clonal localizado em Lavras, MG, identificadas por clones que apresentam desempenhos produtivos contrastantes (RRIM 600, GT 1 e FX 2261), a possibilidade de que a atividade da Rubisco e das principais enzimas que atuam no metabolismo de síntese e hidrólise de sacarose tenha associação com o desempenho produtivo de plantas adultas e em franca produção, pertencentes a esses mesmos clones.

\section{MATERIALE MÉTODOS}

Neste experimento, foram utilizadas plantas de seringueira identificadas pelos clones RRIM 600, GT 1 e FX 2261, pertencentes a um jardim clonal da área experimental do Setor de Fisiologia Vegetal, do Departamento de Biologia, da Universidade Federal de Lavras (UFLA). (BICALHO et al., 2008). O experimento foi conduzido entre janeiro e março de 2006, cujo período é considerado quente e chuvoso. A atividade da Rubisco e das enzimas de síntese e hidrólise de sacarose, avaliada nas plantas do jardim clonal, foi comparada com o desempenho produtivo de plantas adultas dos mesmos clones, com 18 anos de idade e em franca produção, cultivadas em área adjacente ao jardim clonal.

Para as análises estatísticas, utilizou-se o delineamento inteiramente casualizado, em três tratamentos 
(clones) e cinco repetições (plantas), sendo que, os dados referentes à atividade de cada enzima, em cada repetição, foram resultantes de uma média de seis datas de coletas, realizadas a cada duas semanas. A análise de variância foi feita com base na comparação de médias, pelo teste de Tukey, a 5\% de probabilidade.

Foram coletadas amostras de casca e de folhas completamente expandidas - "estádio D", que foram submersas em nitrogênio líquido e, em seguida, acondicionadas sob temperatura de $-86^{\circ} \mathrm{C}$, para posterior utilização. Nas folhas, as extrações de Rubisco e SPS foram feitas conforme Geigenberger \& Stitt (1993), onde, alíquotas de $500 \mathrm{~mL}$ do sobrenadante foram adicionadas a uma coluna de $5 \mathrm{~mL}$, contendo Sephadex G-25 previamente diluído em água, na proporção de 1:1 e o eluato foi utilizado nos ensaios enzimáticos.

O preparo dos meios de reação para a atividade da Rubisco baseou-se em Geigenberger \& Stitt (1993) e Sharkey et al. (1991). Foram preparados dois meios de reação, nos quais avaliou-se a atividade da Rubisco em velocidades inicial $\left(\mathrm{V}_{\text {INICIAL }}\right)$ e total $\left(\mathrm{V}_{\text {TOTAL }}\right)$. Numa placa de Elisa, o meio de reação para $\mathrm{V}_{\text {INICIAL }}$ foi preparado, inicialmente, com um volume de $125 \mu \mathrm{L}$, em solução constituída de bicina pH 8,0 $100 \mathrm{mM}$, EDTA $1 \mathrm{mM}, \mathrm{MgCl}_{2}$ $15 \mathrm{mM}$, DTT $10 \mathrm{mM}, \mathrm{NaHCO}_{3} 9,2 \mathrm{mM}, \beta-\mathrm{NADH} 0,5 \mathrm{mM}$, ATP $2 \mathrm{mM}$, BSA $0,1 \%$, fosfocreatina $5 \mathrm{mM}$, fosfocreatina quinase (PCK) $2 \mathrm{U} \mathrm{mL}^{-1}$, fosfoglicerato quinase (PGK) 40 $\mathrm{U} \mathrm{mL}^{-1}$ e gliceraldeído-3-P desidrogenase (GAP-DH) $40 \mathrm{U}$ $\mathrm{mL}^{-1}$. Uma alíquota de $20 \mu \mathrm{L}$ do extrato dessalinizado foi adicionada ao meio de reação, juntamente com $100 \mathrm{~mL}$ de água. Por último, foram adicionados $5 \mu \mathrm{L}$ de RuBP 20,75 $\mathrm{mM}$, completando-se o volume total do meio de reação para $250 \mu \mathrm{L}$. A preparação do meio de reação para $\mathrm{V}_{\text {TOTAL }}$ seguiu os mesmos procedimentos adotados para $\mathrm{V}_{\text {INICIAL }}$, exceto em relação às concentrações de $\mathrm{MgCl}_{2}$ e $\mathrm{NaHCO}_{3}$, que foram, respectivamente, $20 \mathrm{mM}$ e $25 \mathrm{mM}$. Após a adição de RuBP aos meios de reação, observou-se a oxidação de $\beta$-NADH por 30 minutos, em leitura efetuada a $340 \mathrm{~nm}$. Os resultados foram expressos em nmol CO $2 \cdot \mathrm{g}^{-1}$ matéria fresca. $\mathrm{s}^{-1}$.

O preparo dos meios de reação para a atividade da SPS baseou-se em Foyer et al. (1994), Huber et al. (1989) e Isopp et al. (2000). À semelhança do ensaio com a Rubisco, foram preparados dois meios de reação, para avaliação da atividade da SPS em velocidades seletiva $\left(\mathrm{V}_{\mathrm{SEL}}\right)$ e máxima $\left(\mathrm{V}_{\mathrm{MAX}}\right)$. Para avaliar $\mathrm{V}_{\mathrm{MAX}}$, utilizou-se meio de reação $(70 \mu \mathrm{L})$ com a seguinte composição: $14 \mu \mathrm{L}$ de solução contendo HEPES-KOH pH 7,4 $50 \mathrm{mM}, \mathrm{MgCl}_{2} 12 \mathrm{mM}$, DTT $1 \mathrm{mM}$ e UDPG 12 $\mathrm{mM} ; 2,8 \mu \mathrm{L}$ de uma solução contendo frutose-6-P 12
mM e glicose-6-P 36 mM; $30 \mu \mathrm{L}$ do extrato enzimático dessalinizado; e 23,2 $\mu \mathrm{L}$ de água. Frutose-6-P e glicose6-P foram adicionadas por último, para iniciar a reação. $\mathrm{O}$ meio de reação para $\mathrm{V}_{\text {SEL }}$ foi semelhante ao de $\mathrm{V}_{\text {MAX }}$, exceto pela adição de inibidor $\mathrm{Pi}\left(\mathrm{KH}_{2} \mathrm{PO}_{4}\right) 10 \mathrm{mM}$ e pelas concentrações de frutose-6-P e glicose-6-P, respectivamente alteradas para $2 \mathrm{mM}$ e $6 \mathrm{mM}$.

Os meios de reação para a SPS permaneceram em banho-maria, a $25^{\circ} \mathrm{C}$, por 10 minutos. Depois, adicionaramse $70 \mu \mathrm{L}$ de solução de KOH $30 \%$ a cada meio de reação, seguido de fervura por 10 minutos. Em seguida, adicionaramse $1.000 \mu \mathrm{L}$ de solução de antrona a cada meio de reação, em banho-maria a $40^{\circ} \mathrm{C}$, por 20 minutos. As leituras foram realizadas a $620 \mathrm{~nm}$, conforme Yemm \& Willis (1954).

Nos tecidos da casca, as invertases e a SuSy foram avaliadas pelo método "in vivo", conforme Cairo et al. (2005), sendo que os açúcares redutores foram quantificados conforme Miller (1959), cujas leituras foram feitas a $540 \mathrm{~nm}$.

O desempenho produtivo das plantas adultas foi expresso pela produção de borracha natural, por planta (média de cinco plantas por clone), a cada sangria, nos anos de 2002 a 2005. O sistema de sangria adotado foi o de meia espiral $(1 / 2 \mathrm{~S})$, com duas sangrias por semana, espaçadas de 3 a 4 dias (d/3 e d/4).

\section{RESULTADOS E DISCUSSÃO}

$\mathrm{Na}$ Tabela 1, verifica-se a produção de borracha natural de plantas adultas e em franca produção, dos clones RRIM 600, GT 1 e FX 2261, entre 2002 e 2005.

A produção de borracha natural do clone RRIM 600 foi a maior, entre os clones avaliados, seguida das produções do clone GT 1 e do clone FX 2261 - esse último, com produção várias vezes inferior à dos demais. Esses dados confirmam o desempenho produtivo dos três clones em Lavras, MG, avaliado por diferentes pesquisadores (LIMA et al., 2002; MESQUITA et al., 2006a; OLIVEIRA, 1999). Miguel (2005) encontrou elevados valores de fotossíntese líquida $\left(\mu \mathrm{mol} \mathrm{CO} \mathrm{CO}^{-2} \cdot \mathrm{s}^{-1}\right)$ no clone RRIM 600 , e sugeriu uma possível associação entre esta variável e o desempenho produtivo dos clones. É possível que a produtividade seja um reflexo da variabilidade fotossintética nos clones, embora seja pouco provável que essa se constitua no único fator associado ao desempenho produtivo.

A atividade da Rubisco não diferiu entre os clones RRIM 600 e GT 1, tanto em $\mathrm{V}_{\text {INICIAL }}$ como em $\mathrm{V}_{\text {TOTAL }}$, mas em ambos essa atividade foi superior à do FX 2261 (Figura 1). O estado de ativação da Rubisco variou entre $66 \%$ e $68 \%$. 
Tabela 1 - Produção anual de borracha natural (g látex/sangria/planta) dos clones RRIM 600, GT 1 e FX 2261, cultivados em Lavras, MG, de 2002 a 2005, nos meses de janeiro a março. Os valores correspondem à produção média, por planta (média de cinco plantas), a cada sangria. Os números entre parênteses correspondem ao erro padrão das médias. As letras comparam médias da produção entre clones, num mesmo ano, com base no teste de Tukey, a 5\% de probabilidade. Fonte: Setor de Fisiologia Vegetal da UFLA.

\begin{tabular}{ccccc}
\hline Clone & \multicolumn{4}{c}{ Produção anual de borracha natural (g látex/sangria/planta) } \\
\cline { 2 - 5 } & 2002 & 2003 & 2004 & 2005 \\
\hline RRIM 600 & $62,11( \pm 5,65) \mathrm{a}$ & $59,71( \pm 8,47) \mathrm{a}$ & $53,58( \pm 7,92) \mathrm{a}$ & $57,12( \pm 6,02) \mathrm{a}$ \\
GT 1 & $34,05( \pm 4,87) \mathrm{b}$ & $26,07( \pm 6,11) \mathrm{b}$ & $28,38( \pm 5,39) \mathrm{b}$ & $31,87( \pm 4,45) \mathrm{b}$ \\
FX 2261 & $5,52( \pm 1,98) \mathrm{c}$ & $4,80( \pm 2,13) \mathrm{c}$ & $*$ & $*$ \\
\hline
\end{tabular}

* Informações não disponíveis.

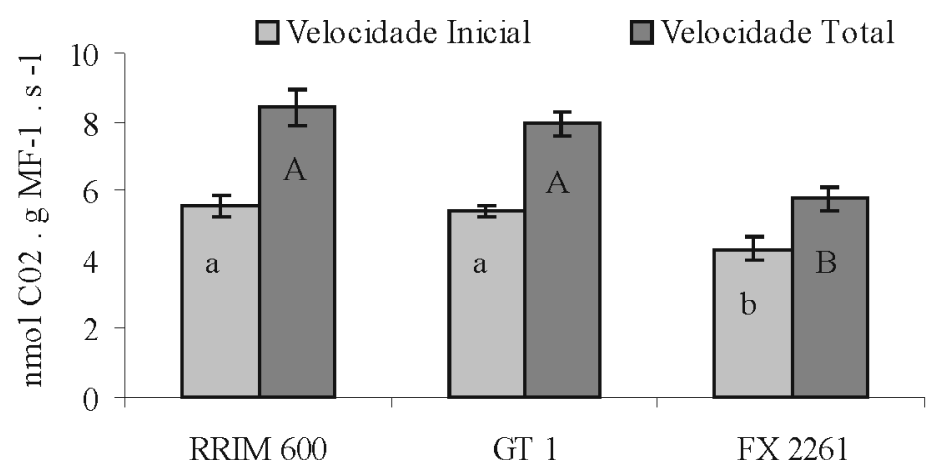

Figura 1 - Atividade da Rubisco em $\mathrm{V}_{\text {INICIAL }}$ (colunas claras) e $\mathrm{V}_{\text {TOTAL }}$ (colunas escuras), nos clones RRIM 600, GT 1 e FX 2261. As barras em cada coluna indicam o erro padrão da média de cinco repetições. Letras minúsculas comparam médias de $\mathrm{V}_{\text {INICIAL }}$, enquanto letras maiúsculas comparam médias de $\mathrm{V}_{\text {TOTAL }}$, com base no teste de Tukey, a $5 \%$ de probabilidade.

Por constituir-se em etapa limitante para a fotossíntese, é comum que a atividade da Rubisco seja investigada como uma das possíveis causas de variabilidade fotossintética entre espécies e clones. Sua participação nas reações de assimilação de $\mathrm{CO}_{2}$ na fotossíntese, através da carboxilação da RuBP, caracteriza envolvimento intenso com os mecanismos fisiológicos e bioquímicos constituintes do sistema fonte-dreno (STITT \& SCHULZE, 1994). Esses resultados sugerem que a atividade da Rubisco pode ser considerada como um dos fatores associados ao desempenho produtivo dos clones (Tabela 1), especialmente quando se observam clones de produtividades mais contrastantes, como RRIM 600 e FX 2261.

A atividade da SPS não diferiu entre os clones, tanto em $V_{\text {SEL }}$ como em $V_{\text {MAX }}$ (Figura 2). A atividade dessa enzima tem se correlacionado com a produção, em outras espécies (GROF et al., 1998; PAVLINOVA et al., 2002; SARQUÍS et al., 1998). Algumas espécies de plantas lenhosas têm revelado correlação positiva entre a atividade da SPS e o crescimento cambial e a formação do cerne no tronco (HAUCH \& MAGEL, 1998; MAGEL et al., 2001; SCHRADER \& SAUTER, 2002). Contudo, os resultados obtidos neste trabalho não apontaram para a atividade da SPS como um dos fatores associados às diferenças de produtividade entre os clones avaliados. O estado de ativação da SPS foi elevado (77\% no RRIM 600, 67\% no GT 1 e 64\% no FX 2261), sugerindo a inexistência de associação entre a atividade dessa enzima e o desempenho produtivo.

A produção de açúcares redutores, resultante da atividade hidrolítica total da sacarose "in vivo", foi semelhante nos clones RRIM 600 e GT 1 e, em ambos, superior à do clone FX 2261 (Figura 3). A hidrólise de sacarose nos três clones ocorreu, predominantemente, por intermédio da invertase ácida total (Figura 4). A atividade da invertase neutra mostrou-se superior à da SuSy apenas nas plantas do clone RRIM 600. Nos demais clones, não houve diferença estatística entre as atividades dessas duas enzimas. 


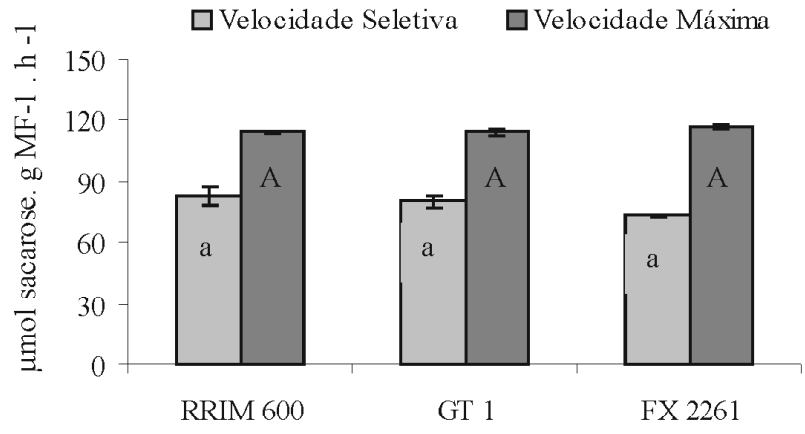

Figura 2 - Atividade da SPS em $\mathrm{V}_{\mathrm{SEL}}$ (colunas claras) e $\mathrm{V}_{\mathrm{MAX}}$ (colunas escuras), nos clones RRIM 600, GT 1 e FX 2261. As barras em cada coluna indicam o erro padrão da média de cinco repetições. Letras minúsculas comparam médias de $\mathrm{V}_{\mathrm{SEL}}$, enquanto letras maiúsculas comparam médias de $\mathrm{V}_{\mathrm{MAX}}$, com base no teste de Tukey, a 5\% de probabilidade.

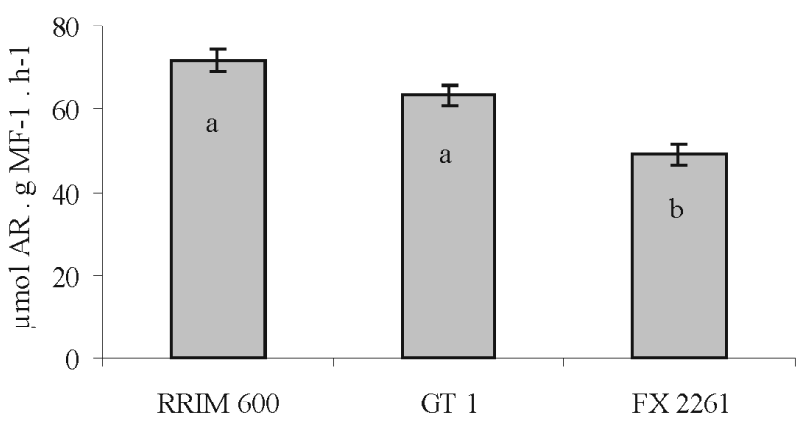

Figura 3 - Atividade hidrolítica total da sacarose "in vivo", representada pela produção de açúcares redutores nos clones RRIM 600, GT 1 e FX 2261. As barras em cada coluna indicam o erro padrão da média de cinco repetições. As letras comparam médias com base no teste de Tukey, a $5 \%$ de probabilidade.

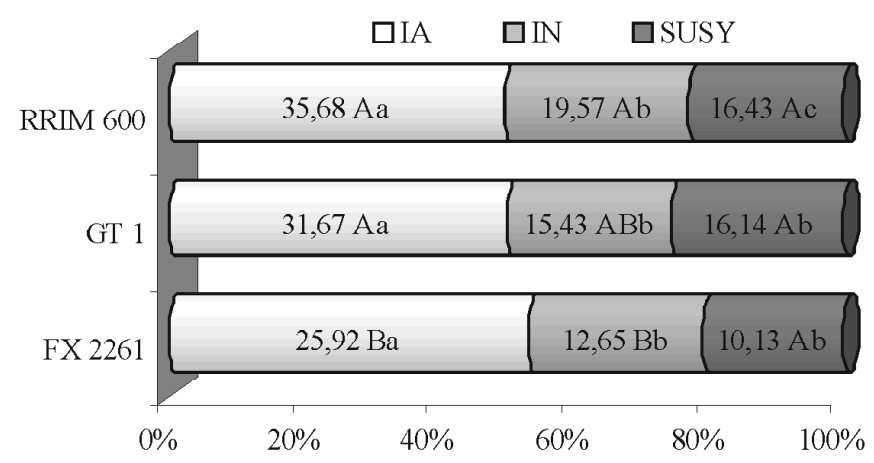

Figura 4 - Participação relativa das enzimas invertase ácida (IA), invertase neutra (IN) e SuSy na hidrólise de sacarose e produção de açúcares redutores, na casca de plantas dos clones RRIM 600, GT 1 e FX 2261. Em cada coluna na horizontal, os números indicam valores absolutos (média de cinco repetições) da produção de açúcares redutores $\left(\mu \mathrm{mol} A \mathrm{AR}_{\mathrm{g}} \mathrm{MF}^{-1} \cdot \mathrm{h}^{-1}\right)$, resultantes da ação de cada enzima, isoladamente. Letras maiúsculas na vertical e letras minúsculas na horizontal comparam médias pelo teste de Tukey, a 5\% de probabilidade.

É possível que a atividade hidrolítica da sacarose seja um reflexo de peculiaridades do método "in vivo", aqui empregado para avaliar a atividade das enzimas sacarolíticas. Por basear-se na incorporação do tecido vegetal fragmentado - e não do extrato enzimático - ao meio de reação, o método "in vivo" permite melhor quantificação da atividade da invertase ácida da parede celular, com reflexos na atividade invertásica ácida total, conforme já haviam constatado Cairo et al. (2005). Por outro lado, admite-se como mais difícil, por esse método, a quantificação da atividade das invertases solúveis (neutra do citosol e ácida do vacúolo) e da SuSy. Para ser hidrolisada, por ação da invertase neutra e da SuSy, a sacarose presente no meio de reação precisa ser transportada, através da membrana plasmática, para o citosol. E, para ser hidrolisada pela invertase ácida vacuolar, a sacarose ainda requer mais um transporte, através do tonoplasto, para chegar ao vacúolo. Cabe ressaltar, ainda, que os açúcares redutores produzidos pela hidrólise dessas enzimas solúveis têm que percorrer o trajeto inverso, ou seja, migrarem do interior da célula para o meio extracelular, a fim de possibilitar a sua quantificação no meio de reação.

O emprego do método "in vivo" tende a favorecer, portanto, a quantificação de açúcares redutores produzidos pela ação da invertase ácida da parede celular. Acreditamos, 
contudo, que essa seja, de fato, a via preferencial de hidrólise da sacarose nos tecidos da casca de seringueira, uma vez que, por diferenças de tamanho das moléculas, as hexoses podem ser transportadas pela membrana plasmática mais facilmente que a sacarose.

Estudos têm demonstrado que alguns aspectos anatômicos da casca podem ter influência decisiva sobre a relação entre a intensidade de hidrólise de sacarose e a produção de látex. Segundo Azzini et al. (1988), a casca é o principal componente do tronco da seringueira responsável pela produção de látex, transporte e armazenamento de assimilados produzidos na folha. Além dos vasos laticíferos, estão presentes na casca, próximo ao câmbio, os elementos de tubos crivados, as células parenquimatosas e os raios medulares.

O número médio de anéis laticíferos é o fator inerente ao clone mais importante do sistema laticífero (WEBSTER \& PAARDKOOPER, 1989), ao passo que o número de vasos laticíferos é um caráter determinante da produção em seringueiras (HO et al., 1973). Mesquita et al. (2006b) verificaram que os números de células e anéis laticíferos são maiores no clone RRIM 600 e menores no clone FX 2261. Essas características podem explicar a variação da atividade sacarolítica entre os clones, observada no presente trabalho.

A partir da hidrólise de sacarose, as hexoses produzidas atuam como moléculas precursoras da síntese de isoprenóides, sendo a borracha a principal substância de caráter isoprenóide do látex. Tendo em vista o desempenho produtivo dos clones (Tabela 1), os resultados referentes à atividade conjunta das enzimas invertases e SuSy sugerem uma possível associação entre esse parâmetro e a produtividade dos clones.

Em relação à maioria das enzimas avaliadas em plantas do jardim clonal, os resultados sugeriram uma provável associação entre a atividade da Rubisco e das invertases e o desempenho produtivo de plantas adultas e em franca produção. Tal associação não se mostrou tão evidente em relação à SPS e à SuSy, cujas atividades foram semelhantes, nos clones avaliados. A hidrólise de sacarose na casca foi exercida, predominantemente, pela ação da invertase ácida. Em proporções menores e equivalentes, essa atividade foi complementada pela SuSy e pela invertase neutra.

\section{CONCLUSÕES}

Em relação à maioria das enzimas avaliadas em plantas do jardim clonal, os resultados sugeriram uma possível associação entre a atividade da Rubisco e das invertases e o desempenho produtivo de plantas adultas e em franca produção. É pouco provável que esse tipo de associação se aplique à SPS e à SuSy, cujas atividades foram semelhantes, nos clones avaliados. A hidrólise de sacarose na casca foi exercida predominantemente pela ação da invertase ácida. Em proporções menores e equivalentes, essa atividade foi complementada pela $\mathrm{SuSy}$ e pela invertase neutra.

\section{REFERÊNCIAS BIBLIOGRÁFICAS}

ALVARENGA, A. P.; CARMO, C. A. F.; MENEGUELLI, N. A.; LIMA, J. A. S.; MOTTA, P. E. F. Determinação do carbono orgânico na biomassa da seringueira em solos de Minas Gerais. Borracha natural. Disponível em: 4http://www.borrachanatural.agr.br/artigos/pdf/ CBCS20032.pdf>. Acesso em: 10 ago. 2003.

AZZINI, A.; GONÇALVES, P. S.; GONDIM-TOMAZ, R. M. A. O diâmetro dos tubos crivados e a produção de borracha em clones de seringueira. Bragantia, Campinas, v. 57, n. 1, p. 57-60, 1998.

BICALHO, K. C.; OLIVEIRA, L. E. M. DE ; SANTOS, J. B. DOS.; MESQUITA, A. C.; MENDONÇA, E. G. Similaridade genética entre clones de seringueira (Hevea brasiliensis), por meio de marcadores RAPD. Ciência e Agrotecnologia, Lavras, v. 32, n. 5, p. 1510-1515, set/out. 2008.

CAIRO, P. A. R.; MESQUITA, A. C.; ASHAN, A. Y. K. V.; OLIVEIRA, L. E. M. Análise comparativa das metodologias "in vitro" e "in vivo" para avaliação de atividade das enzimas invertases e sacarose sintase em seringueira [Hevea brasiliensis (Wild. ex. Adr. de Juss.) Muell. Arg.]. In: CONGRESO ANUAL DA SOCIEDAD COLOMBIANA DE CONTROL DE MALEZAS Y FISIOLOGÍA VEGETAL, 35., 2005, Medellín, Colombia. Anais... Medellín, 2005. p. 24.

FOYER, C. H.; LESCURE, J. C.; LEFEBVRE, C.; MOROTGAUDRY, J. F.; VINCENTZ, M.; VAUCHERET, H.

Adaptations of photosynthetic electron transport, carbon assimilation, and carbon partitioning in transgenic Nicotiana plumbaginifolia plants to changes in nitrate reductase activity. Plant Physiology, Rockville, v. 104, n. 1, p. 171-178, Jan. 1994.

GAMEIRO, A. H. Importação e produção de borracha natural no Brasil. Cepea. Disponível em: 4http://www.cepea.esalqusp.bry. Acesso em: 2 dez. 2004. 
GEIGENBERGER, P.; STITT, M. Sucrose synthase catalyses a readily reversible reaction in vivo in developing potato tubers and other plant tissues. Planta, Berlin, v. 189, n. 3, p. 329-339, Mar. 1993.

GROF, C. P. L.; KNIGHT, D. P.; MCNEIL, S. D.; LUNN, J. E.; CAMPBELL, J. A. A modified assay method shows leaf sucrose-phosphate synthase activity is correlated with leaf sucrose content across a range of sugarcane varieties. Australian Journal of Plant Physiology, Collingwood, v. 25, n. 4, p. 499-502, 1998.

HAUCH, S.; MAGEL, E. Extractable activities and protein content of sucrose-phosphate synthase, sucrose synthase and neutral invertase in trunk tissues of Robinia pseudoacacia L. are related to cambial wood production and heartwood formation. Planta, Berlin, v. 207, n. 2, p. 266-274, Dec. 1998.

HO, C. Y.; NARAYANAN, R.; CHEN, K. T. Clonal nursery studies in Hevea: I. nursery yields and associated structural characteristics and their variations. Journal of Rubber Research Institute of Malaysia, Kuala Lampur, v. 4, p. 305-316, 1973.

HUBER, J. L.; HUBER, S. C.; NIELSEN, T. H. Protein phosphorylation as a mechanism for regulation of spinach leaf sucrose-phosphate activity. Archives of Biochemistry and Biophysics, San Diego, v. 270, n. 2, p. 681-690, May 1989.

INTERNATIONAL RUBBER STUDY GROUP. Production and consumption of natural rubber: rubber industry report. Disponível em:

SWww rubberstudy www.rubberstudy.com/statistics-quarstat.aspx $>$ Acesso em: 22 out. $200 \overline{6}$.

ISOPP, H.; FRENHER, M.; LONG, S. P.; NÖSBERGER, J. Sucrose-phosphate synthase responds differently to source-sink relations and to photosynthetic rates: Lolium perenne L. growing at elevated $p_{\mathrm{CO} 2}$ in the field. Plant, Cell and Environment, Oxford, v. 23, n. 6, p. $597-$ 607, June 2000.

LIMA, D. U.; OLIVEIRA, L. E. M.; SOARES, A. M.; DELÚ-FILHO, N. Avaliação sazonal da produção de borracha e da dinâmica de carboidratos solúveis em plantas de seringueira (Hevea brasiliensis Muell. Arg.) cultivadas em Lavras, Minas Gerais. Revista Árvore, Viçosa, v. 36, n. 3, p. 377-383, jul./set. 2002.
MAGEL, E.; ABDEL-LATIF, A.; HAMPP, R. Nonstructural carbohydrates and catalytic activities of sucrose metabolizing enzymes in trunks of two juglans species and their role in heartwood formation.

Holzforschung, Berlin, v. 55, n. 2, p. 135-145, Feb. 2001.

MESQUITA, A. C.; OLIVEIRA, L. E. M.; CAIRO, P. A. R.; VIANA, A. A. M. Sazonalidade da produção e características do látex de clones de seringueira em Lavras, MG. Bragantia, Campinas, v. 65, n. 4, p. 633-639, 2006a.

MESQUITA, A. C.; OLIVEIRA, L. E. M.; MAZZAFERA, P.; DELÚ-FILHO, N. Anatomical characteristics and enzymes of the sucrose metabolism and their relationship with latex yield in the rubber tree (Hevea brasiliensis Muell. Arg.). Brazilian Journal of Plant Physiology, Vicosa, v. 18, n. 2, p. 263-268, Apr./June 2006b.

MIGUEL, A. A. Comportamento fotossintético e caracterização morfoanatômica de folhas de diferentes clones de seringueira (Hevea spp) em Lavras-MG. 2005. 155 p. Tese (Doutorado em Fisiologia Vegetal) Universidade Federal de Lavras, Lavras, 2005.

MIGUEL, A. A.; OLIVEIRA, L. E. M.; CAIRO, P. A. R.; OLIVEIRA, D. M. Photosynthetic behaviour during the leaf ontogeny of rubber tree clones [Hevea brasiliensis (Wild. ex. Adr. de Juss.) Muell. Arg.], in Lavras, MG. Ciência e Agrotecnologia, Lavras, v. 31, n. 1, p. 91-97, jan./fev. 2007.

MILLER, G. L. Use of dinitrosalicylic acid reagent for determination of reducing sugar. Analytical Biochemistry, Washington, v. 31, n. 5, p. 426-428, 1959.

OLIVEIRA, D. P. Variação sazonal da produção de borracha e da atividade da invertase nos clones RRIM600 e GT-1 de seringueira (Hevea brasiliensis Muell. Arg.]. 1999. 71 p. Dissertação (Mestrado em Fisiologia Vegetal) - Universidade Federal de Lavras, Lavras, 1999.

PAVLINOVA, O. A.; BALAKHONTSEV, E. N.; PRASOLOVA, M. F.; TURKINA, M. V. Sucrosephosphate synthase, sucrose synthase and invertase in sugar beet leaves. Russian Journal of Plant Physiology, New York, v. 49, n. 1, p. 68-73, Jan./Feb. 2002. 
ROCHA NETO, O. G. Eficiência no uso de água em plantas jovens de seringueira (Hevea brasiliensis Muell Arg.) submetidas a déficit hídrico. 1979. 36 f. Dissertação (Mestrado) - Universidade Federal de Viçosa, Viçosa, 1979.

SARQUÍS, J. I.; GONZALEZ, H.; SÁNCHEZ DE GIMENEZ, E.; DUNLAP, J. R. Physiological traits associated with mass selection for improved yield in a maize population. Field Crops Research, Amsterdam, v. 56, n. 3, p. 239-246, Apr. 1998.

SCHRADER, S.; SAUTER, J. J. Seasonal changes of sucrose-phosphate synthase and sucrose synthase activities in poplar wood [Populus $\mathrm{x}$ canadensis Moench (robusta)] and their possible role in carbohydrate metabolism. Journal of Plant Physiology, Jena, v. 159, n. 8, p. 833-843, Aug. 2002.
SHARKEY, T. D.; SAVITCH, L. V.; BUTZ, N. D.

Photometric method for routine determination of kcat and carbamylation of rubisco. Photosynthesis Research, Dordrecht, v. 28, n. 1, p. 41-48, Apr. 1991.

STITT, M.; SCHULZE, D. Does rubisco control the rate of photosynthesis and plant growth? an exercise in molecular ecophysiology. Plant, Cell and Environment, Oxford, v. 17, n. 5, p. 465-487, May 1994.

WEBSTER, C. C.; PAARDEKOOPER, E. C. The botany of the rubber tree. In: WEBSTER, C. C.; BAULKWILL, W. J. (Eds.). Rubber. New York: Longman, 1989. p. 57-84.

YEMM, E. W.; WILLIS, A. J. The estimation of carbohydrates in plant extracts by anthrone. The Biochemical Journal, London, v. 57, n. 3, p. 508-514, 1954. 